[white paper]

Diamond Open Access

\title{
Mudanças climáticas atuais e o futuro da vida no planeta
}

\author{
Colaboração Ciência Aberta ${ }^{1}$ \\ 11 de Dezembro de 2021
}

\begin{abstract}
Resumo
Este é um artigo de divulgação científica em que discutimos, a partir de [1], a ligação entre a ação humana e as mudanças climáticas, bem como seus impactos na vida terrestre.
\end{abstract}

palavras-chave: mudanças climáticas, efeito estufa, aquecimento global, meio ambiente

A versão mais atualizada deste artigo está disponível em https://osf.io/6v2dk/download https://zenodo.org/record/5774024

\section{Preâmbulo}

1. Este artigo foi elaborado a partir de [1], como uma tradução adaptada, seguindo as diretrizes da licença Creative Commons [2].

2. A referência [1], em português, pode ser lida em https://bit.1y/3EouaVw.

${ }^{1}$ Todos os autores com suas afiliações aparecem no final deste artigo. 


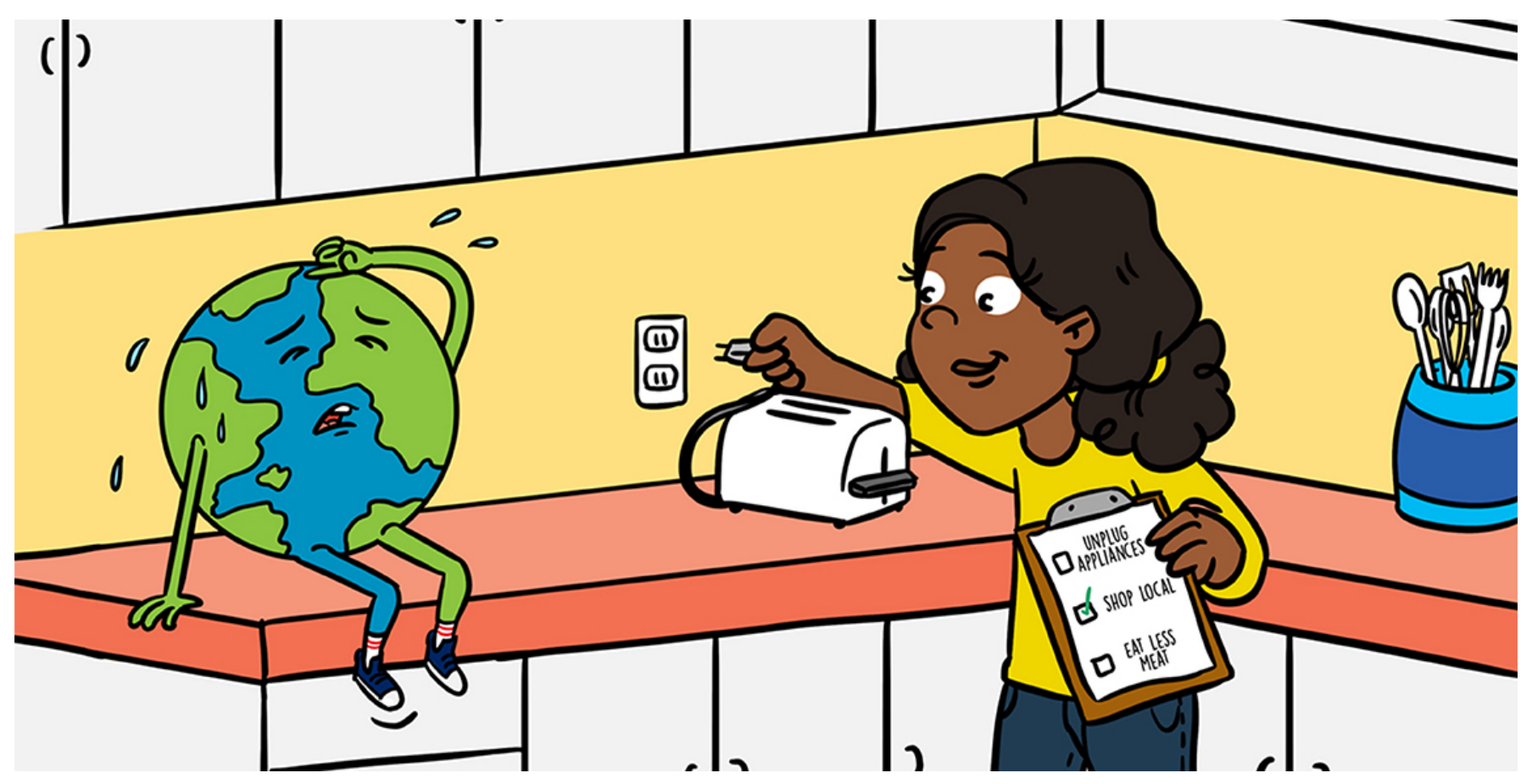

$[1,2]$

\section{Glossário}

3. Combustíveis fósseis: São uma fonte de energia formada pela transformação de restos de plantas e animais mortos que foram enterrados há milhões de anos. Exemplos: petróleo, carvão e gás.

4. Evolução: As mudanças que ocorrem nas formas de vida ao longo de gerações. Geralmente é mais facilmente visto nas características observáveis dos indivíduos, como tamanho, cor do pelo e comportamento.

5. Migração: Movimento de indivíduos de uma espécie para encontrar ambientes mais favoráveis.

6. Neutralidade do Carbono: A quantidade de $\mathrm{CO}_{2}$ produzida é equilibrada pela remoção de uma quantidade igual de $\mathrm{CO}_{2}$ da atmosfera, resultando em nenhuma emissão líquida de carbono. 


\section{Introdução}

7. Desde a Revolução Industrial, o clima da Terra vem mudando rapidamente.

8. As ações humanas são o principal fator que promove esse ritmo intenso de mudanças.

9. Em particular, o uso massivo de combustíveis fósseis (óleo, carvão, gás) libera uma grande quantidade de dióxido de carbono $\left(\mathrm{CO}_{2}\right)$ na atmosfera, que aquece o planeta.

10. Até agora, essa mudança climática não afetou muito a vida na Terra.

11. No entanto, está ameaçando a existência de várias formas de vida que têm que suportar essas mudanças climáticas juntamente com outras mudanças induzidas pelo homem (por exemplo, o desmatamento).

12. Todos esses fatores combinados podem nos afetar em breve também.

13. Por exemplo, a disponibilidade de alimentos pode ser drasticamente reduzida.

14. Neste artigo, falaremos sobre a ligação entre as atividades humanas e as mudanças climáticas, pois a humanidade ainda pode desacelerar seu impacto no planeta Terra.

15. Há muitas coisas que todos nós podemos fazer para ajudar a desacelerar as mudanças climáticas e a extinção de formas de vida em um futuro próximo.

\section{O clima está mudando muito rápido atual- mente e isso não é natural}

16. Você sabe a diferença entre tempo e clima? 
17. O tempo é composto por uma série de propriedades físicas, como temperatura, precipitação, velocidade do vento e muitas outras características que mudam de acordo com as estações, dias ou mesmo horas.

18. Quando consideramos o tempo durante longos períodos (30 anos ou mais), estamos falando sobre o clima.

19. O clima do nosso planeta muda constantemente ao longo das eras (Fig. 1).

20. Alguns períodos de tempo no passado eram consideravelmente mais quentes e outros consideravelmente mais frios do que hoje, e mudanças semelhantes acontecerão no futuro.

21. Há cerca de 20 mil anos, a última fase de resfriamento terminou, iniciando um período de aquecimento até cerca de 8 mil anos atrás, durante o qual a temperatura média da Terra aumentou entre 5,6 e $8,5^{\circ} \mathrm{F}\left(3,1-4,7^{\circ} \mathrm{C}\right)[3]$.

22. Isso significa uma mudança de cerca de $0,06^{\circ} F\left(0,03^{\circ} C\right)$ a cada século.

23. Entre 8 mil anos atrás e a Revolução Industrial (cerca de 200 anos atrás), as temperaturas eram relativamente constantes.

24. Desde então, as temperaturas voltaram a aumentar, e muito rapidamente (Figs. 1A e 2B).

25. Fig. 1A: As mudanças na temperatura média e nos níveis de $\mathrm{CO}_{2}$ nos últimos 100 mil anos.

26. Fig. 1B: As mudanças na temperatura média e nos níveis de $\mathrm{CO}_{2}$ entre os anos 1880 e 2016.

27. Em ambos os casos da Fig. 1 (A, B), a linha azul-vermelha representa as mudanças de temperatura e a linha verde-marrom representa a variação de $\mathrm{CO}_{2}$. 
A)
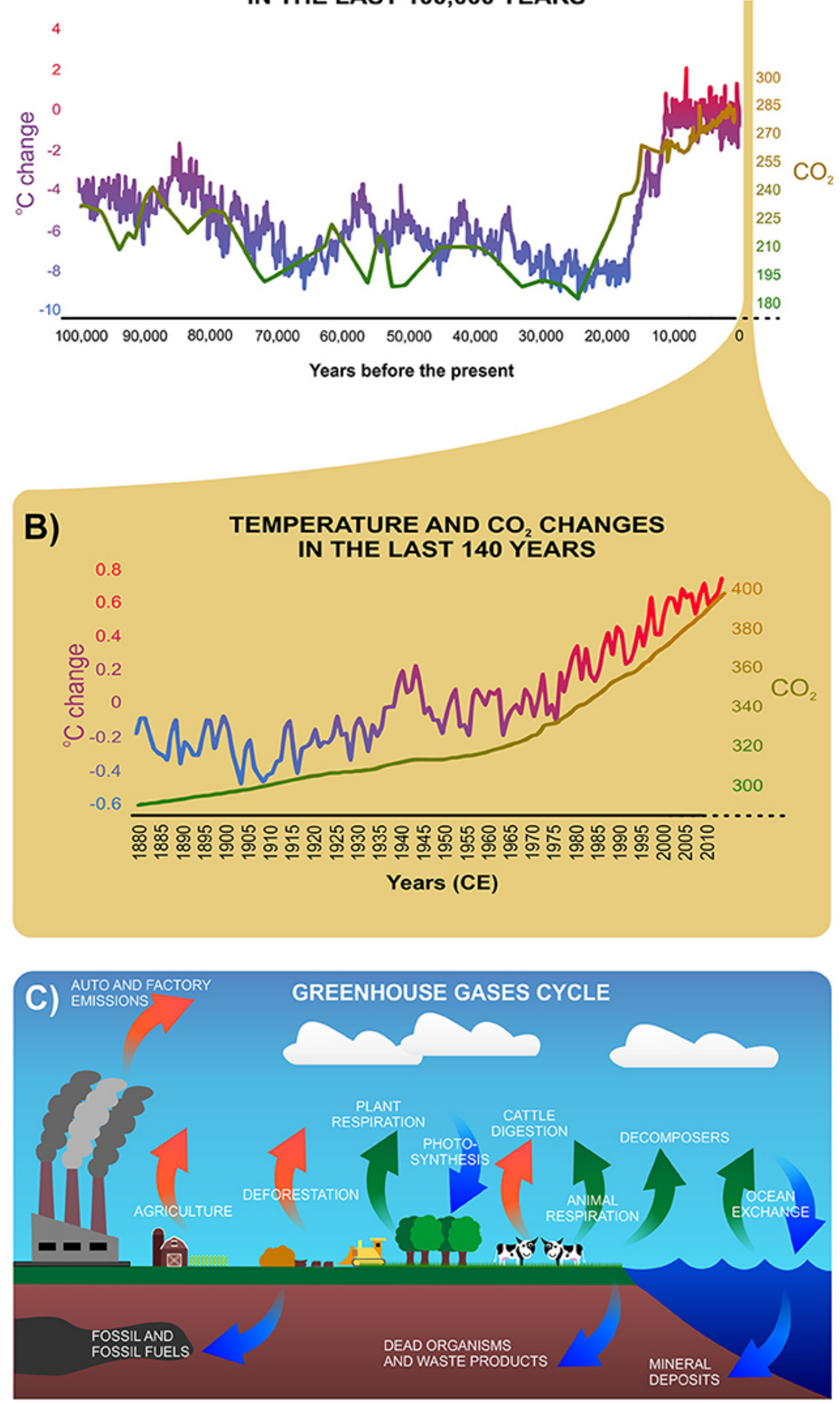

Figura 1: [1]. 
28. A partir desses gráficos, você pode ver claramente que: (1) as mudanças climáticas e a variação de $\mathrm{CO}_{2}$ estão intimamente relacionadas; (2) o clima tem mudado ao longo de milhares de anos; e (3) a Terra está aquecendo rapidamente desde 1880 .

29. Fig. 1C: Os gases de efeito estufa são gases capazes de aquecer a Terra e a atmosfera. A liberação de gases de efeito estufa na atmosfera (setas para cima) e a remoção da atmosfera (setas para baixo) são mostradas. As setas vermelhas representam as emissões antropogênicas e as verdes representam as emissões naturais (os dados de A e B vêm da NASA, EUA, e da Administração Oceânica e Atmosférica Nacional, EUA).

30. No ano de 2100 , os cientistas acreditam que a temperatura média do planeta terá aumentado de 3,6 a $8,8^{\circ} \mathrm{F}\left(2,0-4,9^{\circ} \mathrm{C}\right)$ adicionais em comparação com as temperaturas da época da Revolução Industrial [4].

31. Isso significa que o aumento da temperatura do planeta no próximo século ocorrerá 100 vezes mais rapidamente do que nos últimos 20 mil anos.

32. Enquanto as mudanças anteriores no clima foram resultado de vários fatores, como a quantidade de energia proveniente do sol e a concentração de diferentes gases atmosféricos, desta vez os humanos são os principais responsáveis.

33. Eé por isso que chamamos o aquecimento atual de mudança climática antropogênica (ou induzida pelo homem).

34. Desde a Revolução Industrial, nossa espécie vem queimando imensas quantidades de combustível fóssil para apoiar nossa demanda cada vez maior de energia.

35. Principalmente por meio dessa atividade, nos últimos 200 anos, os humanos aumentaram a quantidade de dióxido de carbono $\left(\mathrm{CO}_{2}\right)$ na atmosfera em cerca de $46 \%$. 
36. E o $\mathrm{CO}_{2}$ não é o único fator que afeta o clima.

37. O uso de combustíveis fósseis, a agricultura, processos industriais e desmatamento emitem outras substâncias (ou evitam que diminuam naturalmente) o que contribui para as mudanças climáticas (Fig. 1C).

38. A mudança climática antropogênica pode não parecer muito para nós agora, mas terá um enorme impacto na humanidade nas gerações atuais e nas próximas.

39. A frequência e a intensidade dos fenômenos naturais, como secas e tempestades, muito provavelmente aumentarão com várias consequências para os seres humanos (Tabela 1).

40. Até mesmo nossas linhas costeiras mudarão dramaticamente com a elevação dos oceanos, principalmente devido ao derretimento das calotas polares.

41. Isso pode resultar no abandono de cidades litorâneas inteiras, como Nova York, Miami, Rio de Janeiro, Amsterdã e Bangkok.

42. A mudança climática também afetará as formas de vida no planeta.

43. Vários micróbios, plantas e animais provavelmente serão extintos.

44. Para se ter uma ideia de como a vida pode mudar em resposta à mudança climática, apenas 6 mil anos atrás, o Deserto do Saara, um dos lugares mais secos da Terra hoje, estava coberto por uma vegetação exuberante.

45. A paisagem verde antes existente era resultado das condições mais úmidas daquela época [5]. 


\begin{tabular}{|ll|}
$\begin{array}{ll}\text { Climate change will result in } \\
\text { more frequent/more intense: }\end{array}$ & And the consequences to humans might be: \\
\hline Heat waves & $\begin{array}{l}\text { Increase of death in elderly and poor } \\
\text { Increase in heat stress in livestock and agriculture } \\
\text { Change in tourism destinations }\end{array}$ \\
Rainfall & $\begin{array}{l}\text { Increase in floods } \\
\text { Increase in soil erosion }\end{array}$ \\
Drought & Decrease in crop and livestock production \\
& $\begin{array}{l}\text { Decrease in quantity and quality of water } \\
\text { Increase in forest fires }\end{array}$ \\
Storms & Increase property and infrastructure losses \\
& Increase in infectious disease epidemics \\
& Increased risk to human life \\
Increase in coastal erosion
\end{tabular}

Tabela 1: Principais impactos diretos na vida humana devido às mudanças climáticas antropogênicas (informações adaptadas do Painel Intergovernamental sobre Mudanças Climáticas) [1]. 


\section{Então, o que acontece com os seres vivos quando o clima muda?}

46. As mudanças climáticas afetam a forma como os seres vivos interagem uns com os outros e com o ambiente onde vivem.

47. Quando enfrentam desafios climáticos, as espécies têm duas opções principais (que também podem acontecer em combinação). A primeira é migrar.

48. Por exemplo, à medida que as temperaturas da superfície do oceano aumentam devido à mudança climática antropogênica, várias espécies de algas a peixes estão se movendo em direção aos pólos em busca de águas mais frias $[6]$.

49. Para a migração acontecer, as espécies devem ser capazes de encontrar outro lugar onde possam sobreviver e prosperar.

50. A migração é mais fácil, como você pode imaginar, para espécies que são capazes de viajar longas distâncias durante sua vida, como baleias e pumas.

51. No entanto, pode ser muito difícil para espécies que não conseguem viajar longas distâncias ou que não dispersam sementes muito longe ou com muita frequência, como as preguiças e as orquídeas, respectivamente.

52. A outra maneira de uma espécie sobreviver é evoluindo. A evolução pode acontecer em pequena escala.

53. Por exemplo, ao longo de algumas gerações, os esquilos alpinos ( $T a$ mias alpinus) do Parque Nacional de Yosemite, Califórnia, EUA, desenvolveram faces mais longas em 100 anos em resposta à mudança climática [7]. 
54. A evolução também pode acontecer em grande escala, resultando na origem de novas espécies.

55. Por exemplo, os ursos pardos (Ursus arctos) e os ursos polares (Ursus maritimus) evoluíram da mesma espécie de urso em um processo que começou por volta de 480-340 mil anos atrás, à medida que os dois grupos acumulavam mais e mais diferenças ao longo do tempo [8].

56. Infelizmente, quando as espécies não conseguem migrar ou evoluir em resposta às mudanças no ambiente, elas se extinguem.

57. O estilo de vida humano e o número cada vez maior de humanos no planeta impõem uma série de desafios para a sobrevivência de várias espécies (Fig. 2).

58. Cerca de duas espécies de vertebrados foram extintas por ano durante os últimos 100 anos, principalmente devido a causas humanas [9].

59. Alguns exemplos dos muitos subprodutos prejudiciais do nosso estilo de vida são o intenso desmatamento devido à agricultura e a poluição do ar e da água.

60. A mudança climática antropogênica merece atenção especial, pois é diferente de outros impactos humanos na natureza.

61. Ela tem um efeito global, mesmo em áreas que raramente são perturbadas por outros impactos humanos, como algumas áreas protegidas.

62. Além disso, a mudança climática antropogênica está acontecendo tão rapidamente que várias espécies não estão conseguindo migrar ou evoluir.

63. Isso significa que a mudança climática antropogênica é uma séria ameaça às espécies que já lutam para sobreviver em uma Terra amplamente transformada pelo homem. 
64. A mensagem para levar para casa é: os humanos estão causando um impacto devastador e duradouro na vida existente na Terra.

65. Para resumir, é possível que mais de $75 \%$ de todas as espécies, três em cada quatro espécies que existem atualmente, estejam extintas daqui a alguns séculos [10].

66. A extinção de formas de vida primorosas é triste em si, mas o problema da extinção vai muito além do simples desaparecimento desses organismos. Contamos com muitos deles para sobreviver.

A)

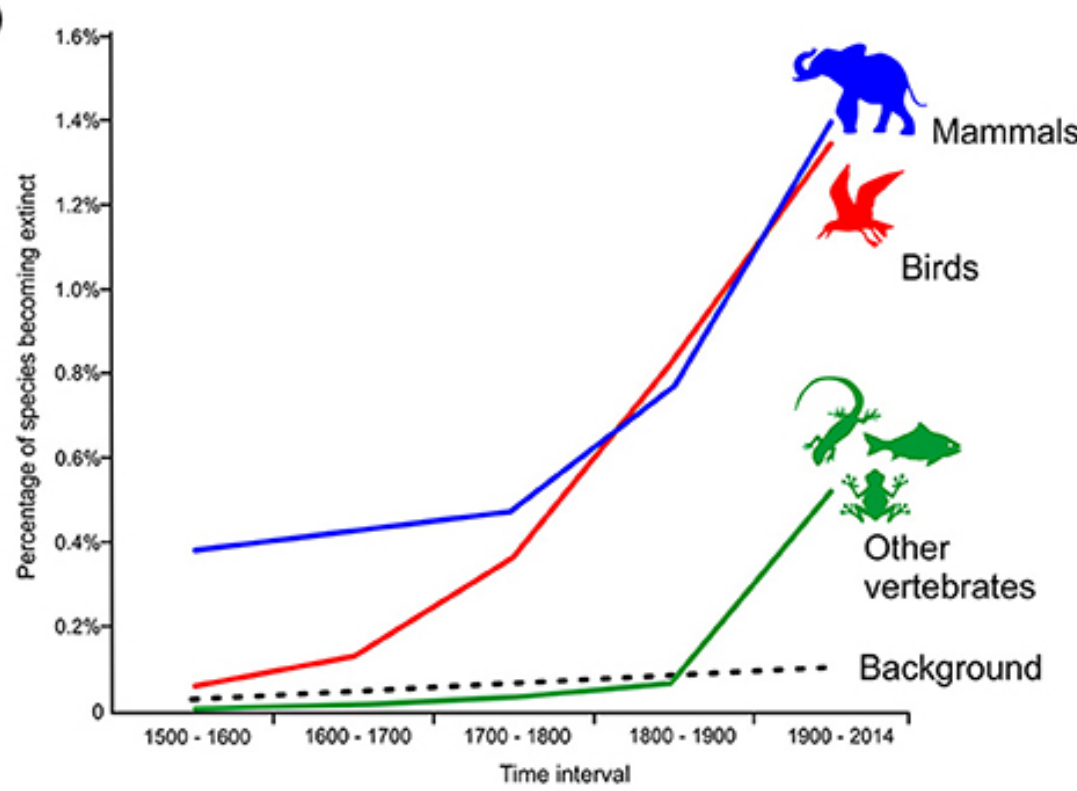

Figura 2: [1].
B) Major causes for anthropogenic species extinction

\begin{tabular}{|c|c|}
\hline WHAT & WHY \\
\hline Climate change & $\begin{array}{c}\text { Alters habitat (like food and water } \\
\text { availability, and presence of other } \\
\text { species) }\end{array}$ \\
\hline Hunting/fishing & $\begin{array}{c}\text { Removes too many individuals } \\
\text { from the population }\end{array}$ \\
\hline Introduced species & $\begin{array}{c}\text { Compete for resources with } \\
\text { original species, and preys on it }\end{array}$ \\
\hline Agriculture & $\begin{array}{c}\text { Alters habitats and pollutes } \\
\text { environment }\end{array}$ \\
\hline Pollution & $\begin{array}{c}\text { Alters the chance of survival and } \\
\text { reproduction rate of species }\end{array}$ \\
\hline $\begin{array}{c}\text { Large human } \\
\text { populations }\end{array}$ & Intensify all other factors \\
\hline
\end{tabular}

67. Fig. 2(A): Taxas de extinção de vertebrados desde o ano 1500. A linha pontilhada ("Background") representa a quantidade de extinção esperada sem influência humana. Nota-se que a quantidade de extinções causadas por humanos aumentou com o tempo e é várias vezes maior do que a taxa de extinção de "Background".

68. Fig. 2(B): Principais formas pelas quais os humanos estão causando extinções (imagem redesenhada de Ceballos et al. [11]). 
69. A qualidade do ar que respiramos, da água que bebemos e dos alimentos que ingerimos, só para citar alguns exemplos, estão diretamente relacionados com a existência e a saúde de várias outras espécies.

70. Além disso, também estudamos outras formas de vida para encontrar soluções para nossos próprios problemas.

71. Por exemplo, o velcro foi desenvolvido após estudar as rebarbas (sementes) de uma planta chamada bardana, que naturalmente se prendem às roupas.

72. Vários medicamentos foram descobertos em diferentes formas de vida e só mais tarde foram sintetizados em laboratórios.

73. Existem inúmeras invenções/descobertas à nossa espera por meio do estudo da natureza, mas elas só estarão disponíveis enquanto as espécies que podem nos ajudar ainda estiverem vivas no planeta.

\section{Seja parte da solução!}

74. Em todo o mundo, as pessoas estão trabalhando juntas para diminuir os efeitos das mudanças climáticas e outros impactos humanos negativos ao planeta.

75. O acordo de Paris, iniciado em 2016, é um bom exemplo disso.

76. Este acordo é um esforço global para evitar que as temperaturas globais aumentem mais de $3,6^{\circ} \mathrm{F}\left(2^{\circ} \mathrm{C}\right)$ em relação ao período anterior à Revolução Industrial.

77. A ideia básica é reduzir drasticamente as emissões globais de $\mathrm{CO}_{2}$ e outras substâncias que contribuem para as mudanças climáticas.

78. Atualmente, 185 países de quase 200, aderiram ao acordo de Paris.

79. A cidade dinamarquesa de Copenhagen também tem um plano ambicioso. 
80. Ela quer se tornar uma cidade de carbono neutro até 2025.

81. Para esse fim, entre outras coisas, a cidade está mudando sua produção de energia de combustível fóssil para energia derivada principalmente de resíduos eólicos e animais/vegetais, reduzindo a quantidade de lixo produzido e transformando a cidade em uma enorme ciclovia.

82. Em vários países, cientistas têm estudado diferentes maneiras de remover o $\mathrm{CO}_{2}$ da atmosfera e transformá-lo em algo útil.

83. Alguns pesquisadores, por exemplo, estão estudando como usar bactérias para transformar o $\mathrm{CO}_{2}$ em combustível.

84. No entanto, em um planeta com mais de 7,6 bilhões de pessoas, todos nós precisamos mudar nossos modos de vida para minimizar as mudanças climáticas antropogênicas.

85. Existem muitas maneiras de cada um de nós fazer a sua parte.

86. Um bom primeiro passo é calcular a pegada de carbono da sua família.

87. A pegada de carbono mede quanto $\mathrm{CO}_{2}$ estamos emitindo para a atmosfera durante um determinado período de tempo.

88. Você pode calcular sua pegada de carbono usando diferentes calculadoras online.

89. Uma das muitas possibilidades é https://coolclimate. berkeley.edu/calculator.

90. E depois de saber sua pegada de carbono, tente reduzi-la!

91. Você ficará surpreso com a quantidade de coisas que fazemos que impactam o planeta.

92. O lado bom é que também existem muitas maneiras simples de reduzir nosso impacto negativo. 
93. Aqui estão algumas coisas fáceis que qualquer um de nós pode fazer para ajudar a prevenir mudanças climáticas antropogênicas: http://www .un.org/sustainabledevelopment/takeaction.

94. Algumas dessas ações fáceis incluem: não compre coisas que não precise, desligue os aparelhos e as luzes que não estiver usando, tome banhos mais curtos, coma menos carne, aves e peixes, compre localmente e de fontes sustentáveis e use sua bicicleta ou transporte público ao invés de um carro, sempre que possível.

95. Ações simples como essas podem fazer uma grande diferença se um número suficiente de nós as executar!

96. Todos devemos tentar reduzir nossas pegadas de carbono o máximo que pudermos, pois assim reduziremos nosso impacto sobre as mudanças climáticas antropogênicas e as consequências negativas relacionadas para a vida na Terra.

97. Vamos mudar o mundo de uma forma mais bacana!

\section{Ciência Aberta}

O arquivo latex para este artigo, juntamente com outros arquivos suplementares, estão disponíveis em [12]. Seja coautor(a) deste artigo, envie sua contribuição para mplobo@uft.edu.br.

\section{Consentimento}

Os autores concordam com [13].

\section{Como citar este artigo?}

https://doi.org/10.31219/osf .io/6v2dk

https://zenodo.org/record/5774024 


\section{Licença}

CC-By Attribution 4.0 International [2]

\section{Referências}

[1] Hubbe A, Hubbe M (2019) "Current Climate Change and the Future of Life on the Planet." Front. Young Minds. 7:37.

https://doi.org/10.3389/frym.2019.00037.

[2] CC. Creative Commons. Attribution 4.0 International (CC BY 4.0) https://creativecommons.org/licenses/by/4.0

[3] Annan, J. D., and Hargreaves, J. C. 2013. "A new global reconstruction of temperature changes at the last glacial maximum." Clim. Past 9:367-76. https://doi.org/10.5194/cp-9-367-2013

[4] Raftery, A. E., Zimmer, A., Frierson, D. M. W., Startz, R., and Liu, P. 2017. "Less than $2^{\circ} \mathrm{C}$ warming by 2100 unlikely." Nat. Clim. Change 7:637-41. https://doi.org/10.1038/nclimate3352

[5] deMenocal, P., Ortiz, J., Guilderson, T., Adkins, J., Sarnthein, M., Baker, L., et al. 2000. "Abrupt onset and termination of the African humid period: rapid climate responses to gradual insolation forcing." Q. Sci. Rev. 19:347-61.

https://doi.org/10.1016/S0277-3791(99)00081-5

[6] Poloczanska, E. S., Brown, C. J., Sydeman, W. J., Kiessling, W., Schoeman, D. S., Moore, P. J., et al. 2013. "Global imprint of climate change on marine life." Nat. Clim. Change 3:919-25.

https://doi.org/10.1038/nclimate1958

[7] Walsh, R. E., Assis, A. P. A., Patton, J. L, Marroig, G., dawson, T. E., and Lacey, E. A. 2016. "Morphological and dietary responses of chipmunks to a century of climate change." Glob. Change Biol. 22:3233-52. https://doi.org/10.1111/gcb.13216 
[8] Liu, S., Lorenzen, E. D., Fumagalli, M., Li, B., Harris, K., Xiong, Z., et al. 2014. "Population genomics reveal recent speciation and rapid evolutionary adaptation in polar bears." Cell 157:785-94.

https://doi.org/10.1016/j.cell.2014.03.054

[9] Ceballos, G., Ehrlich, P. R., and Dirzo, R. 2017. "Biological annihilation via the ongoing sixth mass extinction signaled by vertebrate population losses and declines." Proc. Natl. Acad. Sci. U.S.A. 114:E6089-96. https://doi.org/10.1073/pnas.1704949114

[10] Barnosky, A. D., Matzke, N., Tomiya, S., Wogan, G. O. U., Swartz, B., Quental, T. B., et al. 2011. "Has the earth's sixth mass extinction already arrived?" Nature 471:51-7.

https://doi.org/10.1038/nature09678

[11] Ceballos, G., Ehrlich, P. R., Barnosky, A. D., Garcia, A., Pringle, R. M., and Palmer, T. M. 2015. "Accelerated modern humaninduced species losses: entering the sixth mass extinction." Sci. Adv. 1:e1400253. https://doi.org/10.1126/sciadv. 1400253

[12] Lobo, Matheus P. "Open Journal of Mathematics and Physics (OJMP)." OSF, 21 Apr. 2020.

https://doi.org/10.17605/osf.io/6hzyp

[13] Lobo, Matheus P. "Simple Guidelines for Authors: Open Journal of Mathematics and Physics." OSF Preprints, 15 Nov. 2019. https://doi.org/10.31219/osf .io/fk836 


\section{Colaboração Ciência Aberta}

Caio Matheus Fontinele dos Santos ${ }^{1,2}$

(autor principal, caiofontinele22@gmail.com)

https://orcid.org/0000-0002-9776-7122

Matheus Pereira Lobo $1,2,3$

https://orcid.org/0000-0003-4554-1372

Sheyse Martins de Carvalho ${ }^{1,2}$

https://orcid.org/0000-0003-2250-9919

${ }^{1}$ Universidade Federal do Tocantins (Brasil)

${ }^{2}$ Universidade Federal do Norte do Tocantins (Brasil)

${ }^{3}$ Universidade Aberta (UAb, Portugal) 